\title{
ÁAirman
}

\author{
Jurnal Teknik dan Keselamatan Transportasi
}

\section{Sistem Keamanan di Maneuvering Area bandar Udara Domine Eduard Osok Sorong}

\section{Security System in Maneuvering Area Domine Eduard Osok Airport Sorong}

\author{
Ahmad Bahrawi \\ ahmad.bahrawi@poltekbangmakassar.ac.id \\ Politeknik Penerbangan Makassar
}

\begin{abstract}
ABSTRAK
Bandar Udara Domine Eduard Osok Sorong yang terletak dekat dengan pemukiman masyarakat kota Sorong menyebabkan bandara ini harus memiliki tingkat kewaspadaan yang lebih. Dimana kehadiran pejalan kaki, hewan, maupun pengguna landasan pacu sebagai akses jalan yang menjadikannya sebuah obstruction bagi para pemandu lalu lintas udara maupun pilot dan pihak keamanan bandara. Penelitian ini mencakup ruang lingkup combine service yang dimana hanya satu unit yang bekerja dan hanya menggunakan satu frequency saja yaitu hanya unit Tower yang dimana ATC bertanggung jawab penuh mengatur lalu lintas udara dari ground hingga ketinggian FL245. Kondisi ini diberlakukan untuk menghemat biaya yang keluar dan lebih mengefisiensikan pekerjaan yang dimana traffic di Sorong tidak begitu crowded seperti sebelum pandemi. Kondisi pengamanan di Maneuvering Area Bandar Udara Domine Eduard Osok belum sesuai standard. Banyak penduduk sekitar Bandara yang sering menyebrang runway tanpa mendapatkan izin dari pihak patroli dan ATC baik itu pejalan kaki maupun yang menggunakan kendaraan motor. Masih kurang efisiennya penjagaan pihak patroli terhadap orang yang ingin menyebrang runway di karenakan pihak patroli yang sewaktu waktu tidak berada di tempat. Pemecahan masalah dengan mengadakan sosialisasi keselamatan penerbangan kepada warga yang tinggal di kawasan sekitar bandara kemudian mengundang beberapa tokoh masyarakat untuk melakukan tour bandara dan membangun pos untuk pihak patroli di sekitar area runway 27. Membuat palang atau memasang traffic light di sekitar area runway 27 yang sering digunakan oleh warga untuk menyeberang runway.
\end{abstract}

Kata kunci: Obstruction; Keamanan

\section{ABSTRACT}

Domine Eduard Osok Sorong Airport, which is located close to the community settlement of Sorong, causes the airport to have a higher level of vigilance. Which is the presence of pedestrians, animals, and runway users as road access which makes it an obstruction for air traffic guides and pilots and for airport security. This study covers the scope of combine service where only one unit works and only uses one frequency, namely tower units where ATC is fully responsible for regulating air traffic from ground to fl245 height. This condition is applied to save costs and further streamline the work where traffic in Sorong is not as crowded as before the pandemic. Security conditions at Maneuvering Area of Domine Eduard Osok Airport are still lacking and not standard. Many residents around the airport often cross the runway without getting permission from the patrol and ATC both pedestrians and those using motor vehicles. There is still a lack of efficient patrol guarding of people 
who want to cross the runway because, the patrol is not at any time in place. Solving the problem by conducting flight safety socialization to residents who live in the area around the airport then invite some community leaders to tour the airport and build a post for patrols around the runway 27 area. Create a crossbar or install Traffic light around the runway 27 area that is often used by residents to cross the runway.

Keywords: obstruction; security

\section{PENDAHULUAN}

Bandar Udara Domine Eduard Osok (DEO) Sorong adalah Bandar Udara Unit Pelaksana Teknis (UPT) kelas I yang berada di bawah naungan Direktorat Jendral Perhubungan Udara. Bandara ini terletak di Sorong daratan (Mainland), Provinsi Papua Barat dan berada kurang lebih $4 \mathrm{~km}$ di sebelah timur Kota Sorong.

Sebelumnya, Bandara di Papua Barat bernama Bandar Udara Jefman yang merupakan bandara AFIS yang terletak di pulau Jefman, Kabupaten Raja Ampat dekat dari kota Sorong. Bandara Jefman dulunya memiliki landasan pacu sepanjang 1.650 dan arah 04-22. Dan untuk mencapai bandara Jefman, ATC harus menyebrang ke pulau menggunakan kapal dengan waktu kurang lebih 40 menit hingga 1 jam lamanya. Bandara Jefman berhenti beroperasi sejak Bandar Udara Domine Eduard Osok (DEO) beroperasi pada tahun 2012.

Saat ini, Bandar Udara Domine Eduard Osok Sorong merupakan salah satu Bandar Udara domestik yang memiliki karakteristik panjang landasan pacu sepanjang 2500 meter. Keberadaannya yang terletak dekat dengan pemukiman masyarakat kota Sorong menyebabkan bandara ini harus memiliki tingkat kewaspadaan yang lebih. Yang mana kehadiran pejalan kaki, hewan, maupun pengguna landasan pacu sebagai akses jalan yang menjadikannya sebuah obstruction bagi para pemandu lalu lintas udara maupun pilot dan bagi pihak keamanan bandara.

Dengan adanya Bandar Udara Domine

Eduard Osok Sorong, diharapkan dapat menjadikan kota Sorong sebagai kota transit dan menjadi bandara internasional serta dapat mendukung industri pariwisata di Indonesia bagian timur terlebih Kota Sorong merupakan salah satu pintu gerbang menuju Raja Ampat.
Apabila terdapat pesawat yang akan datang dan sudah melakukan approach ataupun dalam keadaan holding dan melakukan approach, untuk pesawat yang akan berangkat diberikan realease sebelum pesawat yang akan datang tersebut inbound meninggalkan Instrument Approach Fix (15 miles) dan atau pesawat yang akan berangkat menyatakan ready immediate departure.

Penelitian ini mencakup ruang lingkup mengenai Approach Control Procedure. Akan tetapi, semenjak pandemic COVID-19, pelayanan lalu lintas udara di Sorong, yang seharusnya terbagi menjadi dua unit yaitu unit Tower/Aerodrome Control Tower (ADC) dan unit Approach Control Service (APP) berubah menjadi combine service yang dimana hanya satu unit yang bekerja dan hanya menggunakan satu frequency saja yaitu hanya unit Tower yang dimana ATC bertanggung jawab penuh mengatur lalu lintas udara dari ground hingga ketinggian FL245. Kondisi ini diberlakukan untuk menghemat biaya yang keluar dan lebih mengefisiensikan pekerjaan yang dimana traffic di Sorong tidak begitu crowded seperti sebelum pandemi.

Tabel 1. Call Sign dan Radio Frequency

\begin{tabular}{cc}
\hline Call Sign & Radio Frequency \\
\hline Eduard Tower & $118.8 \mathrm{Mhz}$ \\
\hline Secondary Tower & $128.1 \mathrm{Mhz}$ \\
\hline Sorong Approach & $124.2 \mathrm{Mhz}$ \\
\hline Secondary Approach & $118.8 \mathrm{Mhz}$ \\
\hline
\end{tabular}

Penanganan Departing Aircraft

- Sorong Approach meminta clearance level dan squawk number kepada UPG ACC untuk memberikan ATC Clearance kepada Eduard Tower saat ada pesawat yang meminta start engine. 
- Sorong Approach memberikan ATC Clearance kepada Eduard Tower yang telah memberikan start up clearance kepada pesawat setelah memperoleh data flight plan.

- ATC clearance terdiri dari Clearance Limit, Route, Assigned Level, Transponder Code dan other pertinent information.

- Sorong Approach memberikan release untuk pesawat yang akan berangkat sebelum memasuki landasan pacu, ketika berhenti di posisi taxiway dan instruksi keberangkatan yang lain segera mungkin sebelum pesawat lepas landas.

- Eduard Tower melakukan transfer of data departure time ke Sorong Approach segera setelah pesawat airborne.

- Tidak di terbitkan TCP antara Ujung Pandang ACC (UPG) dan Sorong Approach. Transfer dilakukan pada saat pesawat melewati FL245 dan dalam batas Sorong Approach.

- Apabila ada konflik traffic antara pesawat depature dengan pesawat arrivall overflying, penyelesaian traffic harus dikoordinasikan dengan UPG ACC sebelum pesawat lepas landas.

- Untuk pesawat yang berangkat dibawah FL 245 ke arah selatan, utara, dan timur diluar Terminal harus di transfer ke Jayapura FSS. Apabila sambungan komunikasi Jaipur FSS tidak dapat menjangkau pesawat maka terdapat pilihan ditransfer ke Ambon FSS untuk pesawat ke arah selatan, dan ke Babullah Tower untuk pesawat ke arah utara pada TCP atau melewati batas TMA Sorong dan sudah clear dengan traffic lain.

\begin{tabular}{cc}
\multicolumn{2}{c}{ Tabel 2.Route } \\
\hline ROUTE & TCP \\
\hline W 41 & BNDRY \\
W36 & BNDRY \\
W 44 & BNDRY \\
W 67 & BNDRY \\
\hline
\end{tabular}

- Transfer of Control dari Sorong Approach kepada UPG ACC

Pada saat pesawat memotong FL245 atau pada titik/ jarak/ ketinggian yang disepakati oleh kedua belah pihak.

- Transfer of Control dari Sorong Approach kepada Jayapura FSS
Untuk pesawat yang berangkat dibawah FL245 ke arah Selatan, Utara dan Timur diluar Terminal harus di transfer ke Jayapura FSS pada TCP atau melewati batas TMA Sorong dan sudah cleared dengan traffic yang lain.

- Didalam wilayah unit pelayanan Pemanduan Ruang Udara Perum LPPNPI Cabang Sorong secara umum diterapkan separasi sebagai berikut:

Outbound Prosedur untuk IFR / VFR Flight yang menggunakan:

a. RUNWAY 09

1. Pesawat ke arah eastbound after takeoff maintain runway HDG until $1500 \mathrm{ft}$, intercept $R D L 089^{\circ} M I L$ proceed to " $Z Q$ " NDB or follow SID ZQ ID DEPARTURE.

2. Pesawat ke arah Southeast bound after takeoff maintain runway HDG until 1500ft, turn right track $153^{\circ}$ to intercept RDL $135^{\circ}$ "MIL" proceed to JOLAM or follow SID JOLAM ID DEPARTURE.

3. Pesawat ke arah Southwest Bound, after takeoff runway HDG until 1500ft, turn right track $251^{\circ}$ to intercept RDL $230^{\circ}$ "MIL" proceed to PENNY or follow SID PENNY IE DEPARTURE.

4. Pesawat ke arah Southwest Bound, after takeoff runway HDG until 3000ft, turn left proceed to MIL at or above 4000ft join RDL 230 MIL proceed to PENNY or follow SID PENNY IA DEPARTURE.

5. Pesawat ke arah Southwest Bound, after takeoff runway HDG until 1500ft, turn right track $268^{\circ}$ to intercept RDL 250 MIL proceed to APASI follow SID APASI IE DEPARTURE.

6. Pesawat ke arah Southwest Bound, after takeoff runway HDG until 3000ft, turn left proceed to MIL at or above 4000ft join RDL 250 MIL proceed to PENNY or follow SID APASI IA DEPARTURE.

7. Pesawat ke arah west bound after takeoff maintain runway HDG until $1500 \mathrm{ft}$, turn right track $282^{\circ}$ to intercept RDL $268^{\circ} \mathrm{MIL}$ proceed to GOBAL or follow SID GOBAL 1E DEPARTURE.

8. Pesawat ke arah west bound after takeoff maintain runway HDG until 3000ft, then turn left proceed to MIL at or above $4000 \mathrm{ft}$ join RDL $268^{\circ}$ MIL proceed to GOBAL or follow SID GOBAL 1A DEPARTURE. 
9. Pesawat ke arah northwest bound after takeoff maintain runway HDG until $1500 \mathrm{ft}$, turn right track $302^{\circ}$ to intercept RDL $288^{\circ}$ MIL proceed to FIMBA and then following W67 or follow SID FIMBA 1E DEPARTURE.

10.Pesawat ke arah west bound after takeoff maintain runway HDG until $3000 f t$, then turn left track $268^{\circ}$ to intercept RDL 288 MIL proceed to FIMBA or follow SID FIMBA 1A DEPARTURE.

11. Or any other instruction by ATC.

\section{b. RUNWAY 27}

1. Pesawat ke arah east bound after takeoff maintain runway HDG until 1000ft, turn right track $108^{\circ}$ to intercept $088^{\circ}$ MIL proceed to " $Z Q$ " $N D B$ or follow SID $\mathbf{Z Q}$ IA DEPARTURE.

2. Pesawat ke arah southeast bound after takeoff maintain runway HDG until 1000ft, turn right track $099^{\circ}$ to intercept $R D L 135^{\circ}$ MIL proceed to JOLAM or follow SID JOLAM IA DEPARTURE.

3. Pesawat ke arah Southwest Bound after takeoff maintain runway HDG until 1000ft, turn right track $195^{\circ}$ to intercept RDL $230^{\circ}$ MIL proceed to PENNY or follow SID PENNY IB DEPARTURE.

4. Pesawat ke arah Southwest Bound after takeoff maintain runway HDG until 1000ft, turn right track $228^{\circ}$ to intercept $R D L 250^{\circ}$ MIL proceed to APASI or follow SID APASI IB DEPARTURE.

5. Pesawat ke arah west bound after takeoff maintain runway HDG until 1000ft, turn left track $257^{\circ}$ to intercept RDL $268^{\circ} \mathrm{MIL}$ proceed to GOBAL or follow SID GOBAL IB DEPARTURE.

6. Pesawat ke arah northwest bound after takeoff maintain runway HDG until 1000ft, turn right track $304^{\circ}$ to intercept RDL $288^{\circ}$ MIL proceed to FIMBA or follow SID FIMBA 1B DEPARTURE.

7. Or any other instruction dari ATC.

Penanganan Arriving Aircraft

- Segera setelah pesawat berhubungan dengan Sorong Approach, diberi informasi yang tersusun dibawah ini, kecuali pesawat telah menerima informasi dari sumber lain (dari ATIS misalnya):
1. Landasan yang digunakan (runway in use);

2. Informasi cuaca (QAM)

3. Kondisi permukaan landasan (utamanya pada saat turun hujan atau jika ada halhal yang membahayakan)

4. Perubahan status alat bantu navigasi udara baik visual maupun non-visual

- Approach menerima estimate time arrival dari Adjacent ATS Unit yang akan diberikan kepada Eduard Tower.

- Sorong Approach memberikan vacant level kepada UPG ACC sebelum pesawat udara memasuki Sorong Terminal Control Area (TMA) apabila ada konflik traffic yang masih yuridiksi Ujung Pandang ACC.

- Transfer of Control dapat dilihat dilampiran LOCA Antara Ujung Pandang (UPE), Jayapura FSS dengan Sorong Approach.

- Apabila ternyata terbukti bahwa akan terjadi penundaan atas pesawat udara yang datang, operator atau perwakilan yang ditunjuk sedapat mungkin harus diberitahu atas perubahan-perubahan dari penundaan tersebut.

- Pesawat udara yang datang dapat diminta untuk lapor saat meninggalkan atau melewati suatu titik yang signifikan atau alat bantu navigasi atau saat mulai mengikuti prosedur turn atau base turn, atau memberikan informasi lain yang diperlukan petugas Pemandu Lalu Lintas Penerbangan untuk memperlancar pesawat udara yang berangkat dan datang.

Inbound Prosedur untuk VFR Flight yang menggunakan:

a. RUNWAY 09

1. Pesawat dari arah Southwest bound (W41) descend to circuit altitude direct long final runway 09.

2. Pesawat dari arah Northwest bound (W67) descend to circuit altitude join to long final runway 09

3. Pesawat dari arah Southeast Bound (W67) descend to circuit altitude than join to right downwind runway 09.

4. Pesawat dari arah east Bound (W41) descent to circuit altitude than join to right downwind runway 09.

5. Or any other instruction dari ATC. 


\section{b. RUNWAY 27}

1. Pesawat dari arah Northwest Bound (W67) descend to circuit altitude than join to right downwind runway 27.

2. Pesawat dari arah southwest Bound (W41) descend to circuit altitude join to right downwind runway 27.

3. Pesawat dari arah Southeast bound (W67) descend to circuit altitude join left base lage runway 27.

4. Pesawat dari arah east bound (W41) descend to circuit altitude direct final runway 27.

5. Or any other instruction dari ATC.

Inbound Prosedur untuk IFR Flight yang menggunakan:

\section{a. RUNWAY 09}

1. Pesawat dari arah Northwest Bound

- Follow STAR Fimba 1C Arrival or,

- Descend to Altitude 3500 Feet Direct to point ADUAP than make VOR/DME approach runway 09 or,

- Or any other instruction by ATC.

2. Pesawat dari arah Southeast Bound

- Follow STAR Jolam 1B Arrival or,

- Descend to Altitude 3500 Feet Direct to point ADUAP than make VOR/DME approach runway 09 or,

- Or any other instruction by ATC

3. Pesawat dari arah Southwest Bound

- Follow STAR Apasi 1C Arrival or Penny 1C Arrival

- Descend to Altitude 3500 Feet Direct to point ADUAP than make VOR/DME approach runway 09 or,

- Or any other instruction by ATC

4. Pesawat dari arah west Bound

- Follow STAR Gobal 1C Arrival or,

- Descend to Altitude 3500 Feet Direct to point ADUAP than

- Or any other instruction by ATC.

5. Pesawat dari arah east Bound

- Follow STAR ZQ 1 B Arrival or,

- Descend to Altitude 3500 Feet Direct to point ADUAP than make VOR/DME approach runway 09 or,

- Or any other instruction by ATC.

\section{b. RUNWAY 27}

1. Pesawat dari arah Southeast Bound

- Follow STAR Jolam 1C Arrival or,
- Descend to Altitude 3500 Feet Direct to point ELPOV than make VOR/DME approach runway 27 or,

- Or any other instruction by ATC

2. Pesawat dari arah Northwest Bound

- Follow STAR Fimba 1D Arrival or,

- Descend to Altitude 3500 Feet Direct to point ELPOV than make VOR/DME approach runway 27 or,

- Or any other instruction by ATC

3. Pesawat dari arah Southwest Bound

- Follow STAR Apasi 1C or Penny $1 D$ Arrival or,

- Descend to Altitude 3500 Feet Direct to point ELPOV than make VOR/DME approach runway 27 or,

- Or any other instruction by ATC

4. Pesawat dari arah east Bound

- Follow STAR ZQ 1 C Arrival or,

- Descend to Altitude 3500 Feet Direct to point ELPOV than make VOR/DME approach runway 27 or,

- Or any other instruction by ATC

5. Pesawat dari arah West Bound

- Follow STAR Gobal 1D Arrival or,

- Descend to Altitude 3500 Feet Direct to point ELPOV than make VOR/DME approach runway 27 or,

- Or any other instruction by ATC

Dalam memberikan pelayanan lalu lintas penerbangan seorang Air Traffic Controller (ATC) harus memperhatikan keselamatan dan efisiensi lalu lintas udara sehingga arus lalu lintas pesawat udara yang datang dan pergi akan berjalan dengan lancer (Susanto \& Sutrisno, 2018). Namun pada kenyataannya, seringkali terdapat masalah yang terjadi di lapangan dalam proses memberikan pelayanan lalu lintas udara.

Sebagai seorang Pemandu Lalu Lintas Udara kita berpedoman pada 5 Objectives of Air Traffic Services. Dengan begitu seorang ATC dapat memastikan bahwa suatu pesawat yang datang dari suatu bandara dapat mendarat dengan selamat di Bandar Udara Domine Eduard Osok (DEO) Sorong, begitu pula sebaliknya yakni pesawat lepas landas dari Udara Domine Eduard Osok (DEO) Sorong ke bandara tujuan dengan selamat dan juga memiliki tanggung jawab untuk menjamin keselamatan, keteraturan, kelancaran arus lalu lintas di movement dan manoeuvring area. 
Ada contoh kejadian yang terjadi di Bandar Udara Domine Eduard Osok Sorong, sebuah motor yang tiba-tiba melintasi runway tanpa izin kepada pihak ATC ataupun Patroli. Beruntungnya, saat itu tidak ada pergerakan pesawat yang akan melakuan kegiatan landing ataupun takeoff. Ternyata, motor yang ditumpangi oleh tiga orang tersebut menyebrang runway untuk menuju ke arah selatan yang dimana arah selatan bandara terhubung langsung dengan lautan. Setelah di cek oleh pihak Patroli, ternyata di sana mereka sedang melakukan penangkapan ikan di pinggir laut. Beberapa waktu lalu juga, ada dua ekor anjing berada di pinggir runway bagian selatan dan beruntungnya, pada saat itu belum ada traffic akan tetapi bisa membahayakan jika hewan tersebut masuk kedalam runway. Di duga, hewan tersebut berasal dari hutan atau pemukiman warga yang tidak jauh dari kawasan runway.

Tak hanya itu, masyarakat yang tinggal di sekitar kawasan bandara juga sering melintas runway di area runway 27 dari arah utara ke selatan maupun sebaliknya. Hal itu terjadi karena terdapat pemukiman warga yang berada di sebelah selatan runway 27. Alaskan warga sering melintasi runway dikarenakan jalanan dari rumah mereka menuju pusat kota membutuhkan waktu sekitar 30-45 menit sedangkan jika mereka melintasi runway, hanya membutuhkan waktu kurang lebih 10 menit saja. Dan juga, sedang dilakukannya pembangunan proyek oleh pihak UPBU bandara di sisi selatan runway. Meskipun begitu, di daerah tersebut terdapat pihak patroli yang bertugas mengawasi serta berkoordinasi dengan pihak ATC untuk meminta izin ataupun untuk menginfokan keadaan di daerah runway 27.

Pihak patroli selalu berkoordinasi dan meminta izin melalui Handie Talkie (HT) dengan pihak ATC jika ada seseorang atau sekelompok warga desa yang akan melintasi runway tapi, terkadang juga mereka melintas tanpa izin di karenakan pihak patroli memiliki jam istirahat dan pergantian shift pada jam tertentu dan kembali menuju pos yang letaknya berada jauh dari daerah runway 27 sehingga ATC melakukan pengamanan dengan cara menyalakan lampu runway.

Jika traffic sedang ramai, hal tersebut merupakan sesuatu yang cukup menggangu dimana ATC harus fokus dengan menjaga sisi udara dan harus terbagi fokusnya menjaga sisi runway (ground). Hal ini merupakan Hazard untuk keselamatan dan kelancaran lalu lintas udara di bandara DEO Sorong.

Contoh kasus yang lainnya, pada tanggal 16 November 2020, pesawat Garuda 682 destinasi Jakarta-Sorong, mendarat menggunakan runway 09 di bandara DEO pukul 21.17 UTC kemudian ATC mengarahkan pesawat tersebut untuk taxi make 180 turn di runway. Dan pada saat itu, sang pilot memberikan informasi ke ATC bahwa ada seseorang yang berada disisi kanan runway 09 dan posisinya sangat dekat dengan runway. Dan pada saat di teropong dari tower. setelah pesawat berputar dan menuju apron, memang benar ada seseorang yang tiba-tiba menyebrang dari arah selatan menuju ke utara tanpa izin kepada pihak patroli atau pun ATC. Kemudian di hari yang sama, pada pukul 01.37 UTC sebuah pesawat carter unschedule, PKTFS destinasi Sorong-Bali, melakukan taxi menuju runway 27 dan posisinya sudah di taxiway Bravo tiba-tiba harus ditahan karena ada seseorang yang tiba-tiba langsung menyebrang runway dari arah utara menuju keselatan dan kesekian kalinya warga menyebrang tanpa izin dari pihak ATC dan patroli.

Meskipun sampai saat ini belum ada kejadian terkait kecelakaan pesawat yang memakan korban akibat pergerakan hewan maupun kegiatan masyarakat sekitar bandara di kawasan runway Bandara DEO Sorong, tetap saja merupakan

Hal-hal seperti yang penulis sudah jelaskan sebelumnya, seharusnya tidak boleh terjadi. Karena, runway merupakan Kawasan Keselamatan Operasi Penerbangan (KKOP). Dan, KKOP di suatu bandara harus aman dari segala rintangan dan gangguan apapun, termasuk manusia, hewan ternak maupun kendaraan bermotor. Semua objek tersebut dapat menggangu proses takeoff dan landing suatu pesawat dan dapat berakibat fatal bagi penerbangan (Ruman \& Safitri, 2018).

\section{METODE}

Metode penelitian yang digunakan adalah studi kasus Sistem Keamanan di Maneuvering Area Bandar Udara Domine Eduard Osok Sorong. Metode penelitian yang digunakan adalah deskripsi kualitatif. 


\section{HASIL PENELITIAN}

Berdasarkan kajian masalah keamanan di maneuvering area yang telah diuraikan, penulis mencoba memberikan beberapa alternatif penyelesaian terkait kendala yang dihadapi di Perum LPPNPI Cabang Sorong yaitu:

1) Mengadakan sosialisasi keselamatan penerbangan kepada warga yang tinggal di kawasan sekitar bandara kemudian mengundang beberapa tokoh masyarakat untuk melakukan tour bandara yang dimana, mereka diajak berkeliling melihat daerah-daerah terlarang dan terbatas di bandara guna memperlihatkan dan menumbuhkan kesadaran kepada mereka bahwa dampak dari kegiatan melintasi runway tanpa meminta izin kepada pihak yang berwenang merupakan hazard dan dapat menyebabkan kecelakaan pesawat.

2) Membuat palang atau memasang Traffic light di sekitar area runway 27 yang sering digunakan oleh warga untuk menyeberang runway. Traffic light atau palang tersebut di rancang otomatis, dan di control langsung oleh ATC yang di letakkan pada $A F L$ system, agar memudahkan pihak patroli serta pihak ATC untuk memonitor warga yang hendak melintasi runway. Jadi, apabila ada traffic arrival yang sedang approach atau pun traffic departure yang akan berangkat, pihak ATC cukup memonitor dan mengaktifkan palang dan traffic lights yang terdapat pada AFL system serta memudahkan pihak patroli untuk berkoordinasi menginfokan keadaan.

3) Membangun pos untuk pihak patroli di sekitar area runway 27 sehingga patroli dapat mengawasi warga yang ingin melintas di area sekitar dengan efisien dan tidak perlu kembali menuju pos yang letaknya jauh dari daerah runway 27 apabila ingin melaksanakan pergantian jaga.

4) Meningkatkan kerjasama, koordinasi serta kewaspadaan antar patroli dan ATC agar terciptanya pelayanan penerbangan yang prima dan aman.
Tabel 3. Penyelesaian Masalah Metode SMS

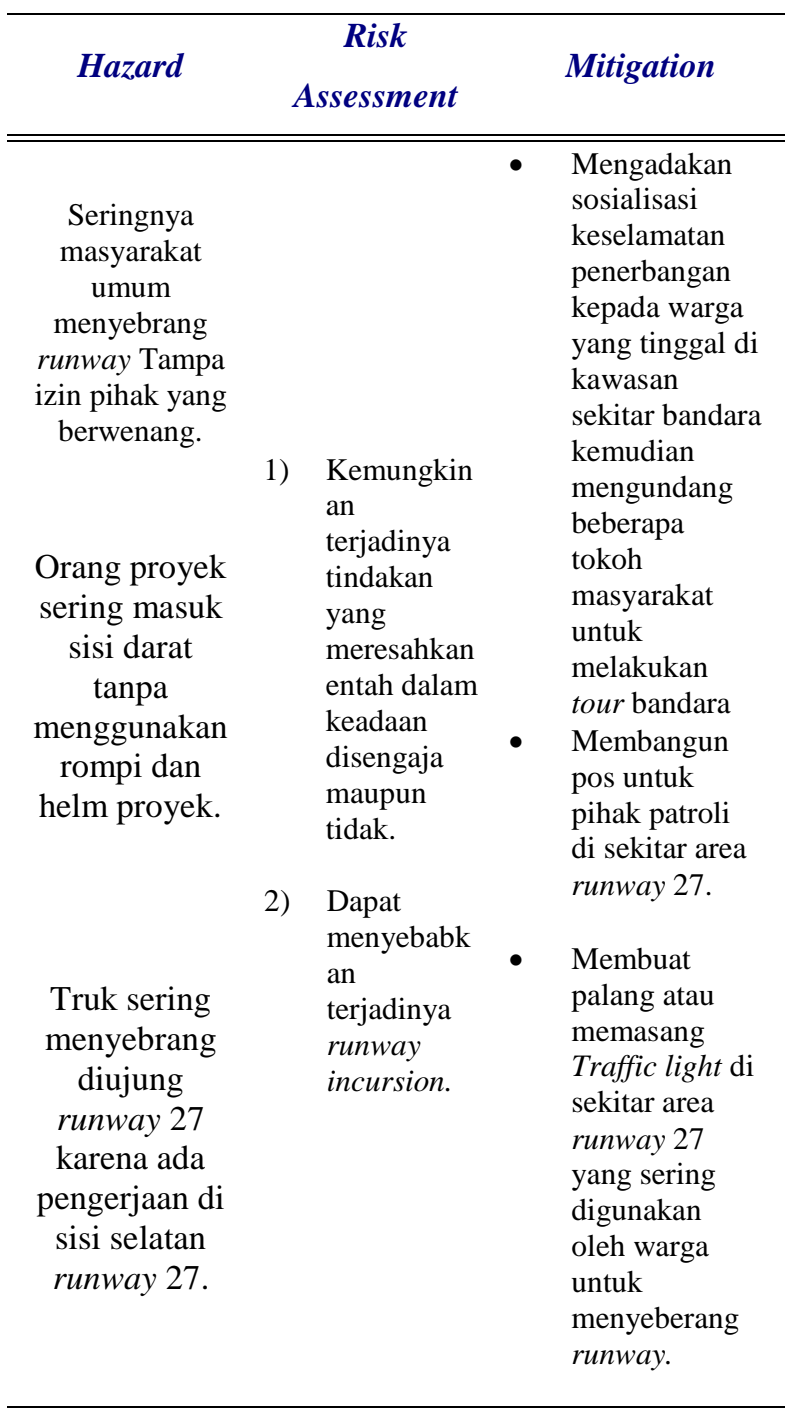

Contoh Gambar Penyelesaian Masalah

Penyelesaian Masalah Menggunakan metode Safety Management System;

1. Airfield Lighting System (AFL) yang dimana merupakan alat bantu pendaratan visual yang berfungsi

membantu dan melayani pesawat terbang selama tinggal landas, mendarat dan melakukan taxi agar dapat bergerak secara efisien dan aman. AFL System ini digunakan oleh $A T C$ di tower apabila ada pergerakan pesawat yang akan takeoff dan landing. Sebagai contoh, penggunaan $A F L$ System tersebut apabila pesawat akan landing, lampu yang dinyalakan untuk 
pendaratan berupa PAPI Lights, Approach Lights, dan Runway.

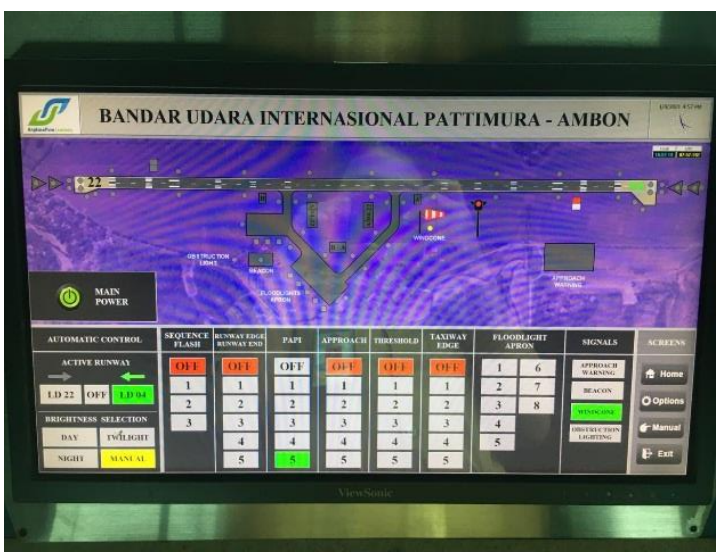

Gambar 1. Contoh AFL System pada Bandar Udara Internasional

2. Traffic lights dan palang dinyalakan apabila ada pergerakan pesawat yang akan landing dan take off sebagai penanda/code kepada pihak patroli agar mencegah orang yang ingin

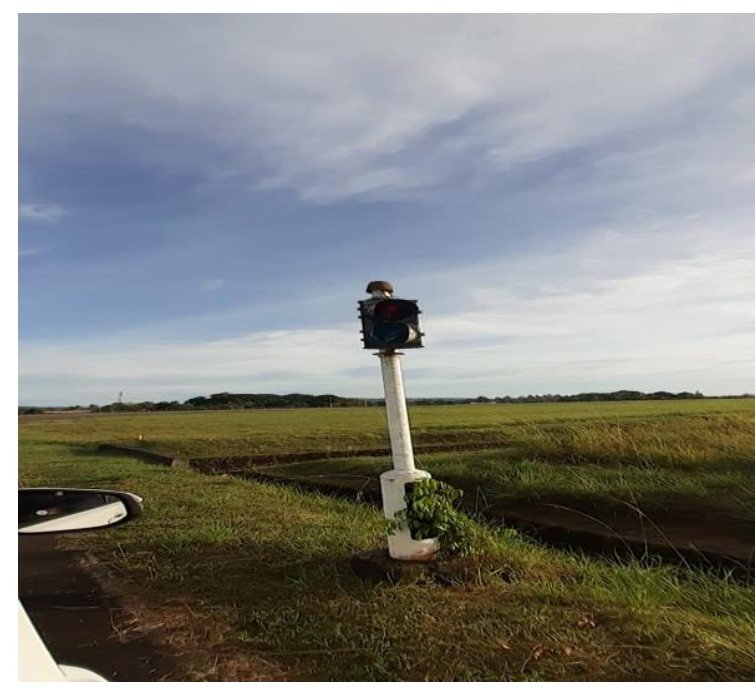

melintas di runway.

Gambar 2. Contoh Traffic Light pada Bandar Udara Internasional Pattimura Ambon

Gambar 3. Contoh Palang Otomatis untuk Area Ujung Runway 27

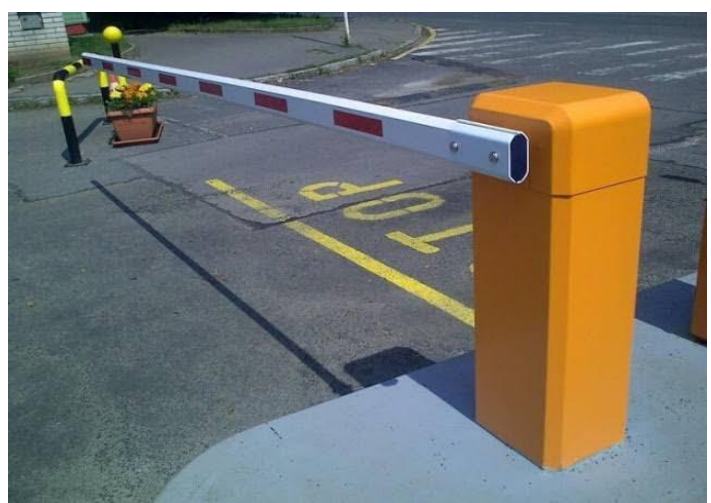

\section{KESIMPULAN}

Dari hasil pembahasan yang telah penulis uraikan, alternatif penyelesaian masalah sangat dibutuhkan demi terciptanya kelancaran dalam prosedur pelayanan lalu lintas udara. Adapun beberapa alternatif telah penulis berikan yang diharapkan dapat dijadikan sebuah pertimbangan dan direalisasikan guna menciptakan pelayanan lalu lintas udara yang aman, efektif dan efisien dalam menunjang keamanan dan kelancaran arus penerbangan di Bandar Udara Domine Eduard Osok.

1. Kondisi pengamanan di Maneuvering Area Bandar Udara Domine Eduard Osok masih kurang dan belum standard.

2. Banyak penduduk sekitar Bandara yang sering menyebrang runway tanpa mendapatkan izin dari pihak patroli dan $A T C$ baik itu pejalan kaki maupun yang menggunakan kendaraan motor.

3. Masih kurang efisiennya penjagaan pihak patroli terhadap orang yang ingin menyebrang runway di karenakan, pihak patroli yang sewaktu waktu tidak berada di tempat.

\section{UCAPAN TERIMA KASIH}

Kami berterima kasih kepada semua pihak yang telah membantu terlaksanaanya penelitian ini.

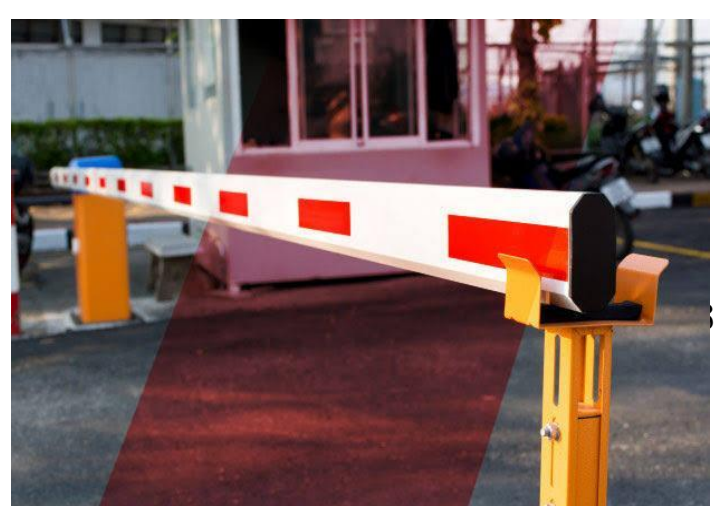




\section{DAFTAR PUSTAKA}

Directorate General of Civil Aviation. 2019. AIRAC AMDT 86. Jakarta.

International Civil Aviation Organization. 2008. Annex 11 Air Traffic Services thirteenth edition

International Civil Aviation Organization. 2013. Annex 14: Aerodrome.

International Civil Aviation Organization. 2013. Annex 17: Security

International Civil Aviation Organization. 2016. Doc.4444 Air Traffic Management: International Civil Aviation Organization

International Civil Aviation Organization. 1983. Doc 9137 Airport Services Manual. Canada: International Civil Aviation Organization

International Civil Aviation Organization. 8973. Doc 8973 Aviation Security Manual. Canada: International Civil Aviation Organization

Peraturan Pemerintah Republik Indonesia. 2001. Nomor 3 Tentang Keamanan dan Keselamatan Penerbangan

Peraturan Menteri Perhubungan Republik Indonesia Nomor: PM 80 Tahun 2017 Tentang Program Keamanan Penerbangan Nasional

Perum LPPNPI Cabang Sorong. 2020. Standard Operational Procedure (SOP) Perum LPPNPI Cabang Sorong Tahun 2020

Rusman, \& Safitri, R. (2018). Design of a DVOR Shelter Security System at Sam Ratulangi International Airport Manado. Airman: Jurnal Teknik Dan Keselamatan Transportasi, 1(1), 11-16. https://doi.org/10.46509/ajtk.v1i1.29

Susanto, A., \& Sutrisno, A. (2018). Analysis of Security Standards on Aviation Safety at Komodo Labuan Bajo Airport. Airman: Jurnal Teknik Dan Keselamatan Transportasi, 1(1), 1-5. https://doi.org/10.46509/ajtk.v1i1.51.
Undang-Undang Republik Indonesia. 2009. Nomor 1 Tahun 2009 Tentang Penerbangan Pasal 338 